\title{
Visualidades urbanas e poéticas da resistência: reflexões a partir de dois itinerários de pesquisa'
}

\author{
Urban and poetic visualities of resistance: reflections from \\ two schedules of research
}

\section{Guilhermo Aderaldo}

Doutor em Antropologia pela USP, membro do Grupo de Estudos de Antropologia da Cidade (Geac) USP). É autor do livro "Reinventando a cidade: uma etnografia das lutas simbólicas entre coletivos culturais vídeo-ativistas nas 'periferias' de São Paulo" (Annablume, 2017) e um dos organizadores do livro "Práticas, conflitos, espaços: pesquisas em antropologia da cidade" (Gramma, 2019).

\section{Resumo}

Neste artigo, busco demonstrar o modo pelo qual uma diversidade de integrantes de coletivos dedicados a diferentes modalidades de ativismo cultural em cidades como São Paulo, Rio de Janeiro e Buenos Aires, tem se valido do uso "tático" de ferramentas tecnológicas, gráficas e comunicativas, com o propósito de produzir referenciais simbólicos que se mostrem capazes de, por um lado, interpelar crítica e publicamente determinados imaginários hegemônicos sobre territórios e populações marginalizadas e, por outro, formular teorias originais, que sirvam de alternativa epistêmica para o entendimento das relações de poder que modulam o governo dos espaços e das populações nas cidades sul-americanas contemporâneas. Para isso, valer-me-ei de um conjunto de dados produzidos no decorrer de duas pesquisas etnográficas recentes, envolvendo o tema da relação entre juventudes, ativismos culturais e novas mobilidades.

Palavras-chave: Cidade, Mobilidades, Juventudes, Territórios, Ativismos.

\footnotetext{
Agradeço à Fapesp pelos financiamentos às pesquisas de doutorado (Processo no 2009/50153-2) e pós-doutorado (Processo no 2014/04243-8 e Processo No 2017/04416-8), que deram lugar à presente reflexão. Lembro ainda que as opiniões, hipóteses e conclusões ou recomendações expressas neste material são de minha responsabilidade e não necessariamente refletem a visão da Fapesp.
} 


\section{Abstract}

In this article, I try to demonstrate how a diversity of members of collectives dedicated to different cultural activisms in cities such as São Paulo, Rio de Janeiro and Buenos Aires have applied a "tactical" use of technological, graphic and communication tools, with the purpose of producing symbolic references capable of criticizing certain hegemonic imaginaries about marginalized territories and populations and formulating original theories that serve as an epistemic alternative for the understanding of power relations which modulate the government of the space and population in the contemporary South American cities. For this purpose, I will use a set of data produced in the course of two recent ethnographic researches, involving the theme of the relationship between youths, cultural activisms and new mobilities.

Keywords: City, Mobilities, Youth, Territories, Activism.

\section{INTRODUÇÃO}

A cidade é feita, essencialmente, de movimento. (AGIER, 2015, p. 484)

Há alguns anos, venho trabalhando com distintas pesquisas etnográficas voltadas, mais especificamente, à tentativa de compreender o impacto que a relativa popularização do acesso às tecnologias de comunicação tem gerado sobre as formas de identificação, mobilidade e engajamento político, sobretudo entre populações jovens, direta ou indiretamente vinculadas a regiões marcadas por processos de precarização e/ou marginalização sociourbana, em diferentes metrópoles sul-americanas, como São Paulo, Rio de Janeiro e Buenos Aires.

No decorrer dessas pesquisas, uma preocupação transversal tem sido a tentativa de demonstrar como um conjunto heterogêneo de pessoas - articuladas coletivamente em torno de redes com desdobramentos, inclusive, transnacionais - vêm sendo capazes de produzir e revelar, por meio de práticas de 
ativismo cultural e do desenvolvimento de formulações epistêmicas e experimentos pedagógicos originais, formas renovadas de entendimento das dinâmicas que marcam as relações de proximidade e distância entre territórios e populações acentuadamente caracterizados por situações de desigualdade.

Tomando, portanto, como plano de referência este recente repertório de pesquisas, buscarei, no decorrer do artigo, elucidar a potência heurística das práticas protagonizadas pelos sujeitos investigados, especialmente no tocante à interpelação de aspectos do fenômeno que vem sendo denominado por alguns autores como "urbanismo militar" (GRAHAM, 2016)2. Similarmente, farei apontamentos sobre o modo como estes interlocutores têm logrado êxito em desenvolver inovadoras ferramentas conceituais, com vistas a apreenderem o sentido dos litígios que marcam as cidades contemporâneas, a partir de seus próprios termos.

Para tanto, começo apresentando alguns casos acompanhados durante a realização de minha investigação de doutorado, na qual estudei o tema do videoativismo em São Paulo. Em seguida, abordo questões trabalhadas na atual pesquisa de pós-doutorado, a partir da análise de atividades que nomeio como "ativismos contrageográficos", e cujos desdobramentos venho acompanhando, desde 2015, em distintas metrópoles sul-americanas.

Por fim, ao justapor aspectos relacionados a estas duas investigações, pretendo explicitar a importância da utilização de métodos que levem em consideração a dimensão das "mobilidades" (SHELLER; URRY, 2006; CRESSWELL, 2006, 2009; CARMO, 2009; AGIER, 2011, 2013, 2015; AUGÉ, 2010), para compreendermos os processos responsáveis pelo desenvolvimento de representações geográficas alternativas, como as que vêm sendo coletivamente

\footnotetext{
Stephen Graham (2016) chama de "urbanismo militar" um conjunto de práticas de gestão urbana apoiadas em representações maniqueístas que têm, cada vez mais, demonizado as cidades (principalmente as áreas mais precárias) como ambientes intrinsecamente ameaçadores, gerando como consequência formas de controle espacial marcadas por uma lógica militar, que entende a diferença como um problema a ser permanentemente combatido por meio de ações securitárias e operações de controle da vida cotidiana, sobretudo de populações entendidas como "de risco", como pobres, migrantes, jovens, ativistas etc. Dentro desta lógica "securocrática", busca-se associar à forma repressora dos projetos ditos de "pacificação", "requalificação", "reordenamento", "revalorização", certo fundamentalismo de mercado, que consiste na padronização da paisagem urbana por meio da introdução de ilhas de consumo e vigilância, por um lado, e por outro, em um conjunto de iniciativas "empreendedoras", visando converter os "pobres" em novos consumidores e trabalhadores precários dos mercados em expansão.
} 
produzidas pelos sujeitos investigados, com o intuito de notabilizarem os sistemas de poder que organizam hierarquicamente as cidades e suas desigualdades.

Sustento que a perspectiva "móvel" oferece-nos a possibilidade de ler a experiência destes interlocutores de maneira relacional, ou seja, a partir de referências não redutíveis nem à lógica sedentária de teorias baseadas em concepções binárias fixas, do tipo centro/periferia, global/local, exclusão/inclusão, legal/ ilegal, lugar/não lugar e nem ao romantismo das leituras pós-modernas e/ou nômades, que apostam na positivação dos fluxos ao mesmo tempo que negligenciam a importância dos territórios e das ancoragens que eles produzem na experiência concreta dos sujeitos. Passemos, a seguir, aos casos mencionados.

\section{EXPERIÊNCIAS DE PESQUISA ENTRE JOVENS VIDEOATIVISTAS NAS “PERIFERIAS” DE SÃO PAULO}

Este primeiro caso empírico envolve uma breve análise retrospectiva de minha experiência de pesquisa junto a uma rede de jovens comunicadores populares politicamente engajados, chamada Coletivo de Vídeo Popular (CVP), a qual estudei durante o doutorado, entre os anos de 2009 e $2013^{3}$.

De maneira sucinta, essa rede surgiu em 2007, tendo como um de seus principais desafios desenvolver um sistema autônomo de comunicação entre áreas e populações marginalizadas de São Paulo. Dela faziam parte, no momento da pesquisa, desde coletivos independentes, formados por jovens egressos de cursos de educação audiovisual, os quais vinham sendo amplamente ofertados por ONGs em diversas regiões periféricas de São Paulo ${ }^{4}$, até núcleos de mídia vinculados a importantes movimentos sociais, como a Brigada Audiovisual da Via Campesina, ligada ao Movimento dos Trabalhadores Rurais Sem Terra (MST).

Interessei-me em pesquisar o CVP justamente porque queria, naquela altura, entender que tipo de relações de reciprocidade se desdobravam dessa

\footnotetext{
3 Ver, especialmente, Aderaldo (2017a).

4 Para uma visão mais detalhada deste processo, ver Aderaldo (2016, 2017a, 2017b, 2017c, 2017d).
} 
experiência associativa. Também queria compreender que tipo de filmes eram produzidos pelos coletivos membros e até que ponto a rede era, realmente, capaz de desenvolver um sistema de comunicação audiovisual responsável por integrar áreas marginalizadas de toda a cidade.

Na medida em que iniciei a pesquisa de campo, passando a acompanhar e a me familiarizar com as reuniões, exibições, debates e discussões que costumavam acontecer entre os coletivos que integravam essa associação ${ }^{5}$, fui me dando conta de que as questões envolvidas naquele universo eram bem mais complexas e abrangentes do que eu, inicialmente, imaginava.

Não levei muito tempo para perceber, por exemplo, que os sujeitos que haviam se tornado meus interlocutores privilegiados de pesquisa não apenas se opunham a certas representações estigmatizantes, produzidas pelo cinema comercial e pelos veículos tradicionais de mídia, conforme eu já supunha; mas, também, discutiam com muita frequência táticas coletivas de oposição a todo um emaranhado institucional vinculado ao "terceiro setor", cuja base comum era a adesão ao princípio da, assim chamada, "responsabilidade social". Tratava-se de pessoas com uma clara consciência crítica a respeito do modo pelo qual versões reificadas e estereotipadas de suas atribuições identitárias "periféricas" costumavam ser manipuladas em ambientes como ONGs, empresas patrocinadoras de "projetos sociais", centros culturais, entre outros lugares pelos quais circulavam.

Seu principal descontentamento residia no fato de que, nos espaços institucionais, estes sentiam que deixavam de ser percebidos como sujeitos políticos, reivindicando o direito a um sistema democrático e plural de comunicação, assim como a um modelo urbano mais justo, sendo, em vez disso, compreendidos na chave moral da "compaixão" (FASSIN, 2014), como jovens "excluídos", sempre à espera de “oportunidades". Desse modo, sentiam-se figurando como

\footnotetext{
Durante o período da pesquisa, o CVP costumava organizar reuniões mensais em diferentes partes da cidade, além de possuírem uma lista de e-mails, através da qual diversos temas eram discutidos. Fora o acompanhamento destas reuniões e debates, também segui mais proximamente as atividades cotidianas de sujeitos vinculados a dois coletivos que integravam a rede, a saber, o coletivo Cinescadão, cuja base ficava na Favela do Peri, localizada no extremo norte de São Paulo, e o coletivo Núcleo de Comunicação Alternativa (NCA), que tinha como base algumas regiões situadas no extremo sul desta mesma metrópole. Ver detalhes em Aderaldo (2016, 2017a, 2017b, 2017c, 2017d).
} 
uma espécie de "outro" ontológico daquilo que, numa concepção normativa e fechada, corresponderia à "cidade", o que fazia com que todo o crédito de suas ações e reivindicações passasse para as mãos de empresários e gestores de projetos socioculturais, reconhecidos como os garantidores das tais "oportunidades".

Tal visão fica evidente através de falas como a de Flávio Galvão, membro do coletivo Cinescadão ${ }^{6}$, quando, num fim de tarde, após sairmos de uma reunião de seu coletivo, disse-me as seguintes palavras:

A gente vira bonequinhos que os caras [gestores de projetos institucionais] manipulam $[\ldots]$. É isso a periferia deles. Fazem a gente se matar pelos [financiamentos destinados aos] projetos e depois ficam se dando créditos que, no fundo, são resultados do nosso trabalho. Com a grana dos projetos, a gente quer conseguir equipamentos para correr junto com movimentos sociais, com um pessoal que quer tomar a rua, isso sim. Não é para ficar fazendo propaganda para nenhum gestor ou político não. Mas enquanto não temos condições, vamos fazendo do jeito que dá. [...] O que eles [gestores culturais] querem, é que a gente diga que a periferia é linda, que tem poesia lá, que estamos mudando o mundo. Que agora nós, os periféricos, é que vamos mostrar como somos. Essa papagaiada toda esconde muita coisa mano [...] (Flávio Galvão, Cinescadão, grifos meus).

Falas como a de Flávio se repetiam a todo momento no campo. E mostravam com clareza a forma pela qual o alargamento da circulação destas pessoas, como aprendizes ou trabalhadores precários das instituições do terceiro setor, estudantes universitários ou ainda como militantes, simultaneamente engajados em múltiplos movimentos culturais e políticos ${ }^{7}$, costumava gerar um enorme

\footnotetext{
6 O Cinescadão era um dos coletivos que integravam a rede CVP, e sua formação contava com a presença do artista visual Thiago Go, dos rappers Shirley Casa Verde, Cézar Sotaque e Paulinho, além de Flávio. Ver detalhes em Aderaldo (2016, 2017a, 2017b, 2017c, 2017d).

7 Além de muitos deles já trazerem em suas trajetórias pessoais um histórico de vínculo com diferentes movimentos, como o Punk, o Hip Hop, o Movimento Negro, movimentos de luta por moradia etc., também costumavam atuar profissional e precariamente no mercado do "terceiro setor", seja prestando pequenos serviços como fotógrafos ou cinegrafistas, seja atuando como arte-educadores. Também costumavam participar de cursos e debates oferecidos por ONGs, centros culturais e órgãos públicos, em diferentes partes da cidade. Muitos eram universitários ou possuíam diploma de ensino superior, na maior parte dos casos em universidades particulares e com bolsas de estudo subsidiadas pelo Ministério da Educação, como o Programa Universidade para Todos (Prouni).
} 
conhecimento a respeito da cidade e dos modos de funcionamento da economia política baseada na noção de "responsabilidade social".

Para Flávio, portanto, assim como para outros interlocutores, os efeitos aparentemente benéficos de certos financiamentos culturais voltados especificamente às "periferias", com base em percepções normativas desse termo, poderiam converter-se numa verdadeira armadilha ideológica, dado que a gramática institucional fundada no mencionado princípio da "responsabilidade social" tenderia, em muitos casos, a transformar questões relativas à "desigualdade", no tocante ao acesso a direitos, em simples noções vinculadas à "diferença" cultural, as quais seriam traduzidas nos termos das demandas identitárias.

Flávio, por exemplo, era um dos que entendia que a sedutora linguagem dos "projetos culturais", na medida em que transformava a "periferia" num paradigma identitário positivo, associado à ideia de "diversidade cultural", poderia fazer com que a crítica às formas de exploração e dominação, bem como a seus efeitos sociais - por exemplo, o genocídio da população jovem e negra - cedesse espaço a uma perspectiva centrada no estímulo à produção e difusão de novos "produtos" (músicas, filmes, artes visuais etc.) identificados com a marca da "cultura da periferia", para o consumo nos mesmos termos do mercado cultural hegemônico. Com isso, uma variedade de coletivos, como o Cinescadão, ao qual ele pertencia, tenderia a transformar-se no que, em suas palavras, seriam "pequenas empresas culturais", formadas por um exército de jovens desempregados ou precariamente empregados e voltadas a uma cruel competição por recursos, ao contrário de núcleos destinados ao fortalecimento de processos reivindicativos e insurgentes na metrópole paulista.

Outro comentário que exemplifica a complexidade das reflexões destes interlocutores foi dado por Daniel Fagundes, que, na época da pesquisa, era membro do coletivo Núcleo de Comunicação Alternativa (NCA) ${ }^{8}$, o qual, assim como o Cinescadão, fazia parte da rede CVP. Destaco o seguinte trecho:

\footnotetext{
Assim como o Cinescadão, comentado anteriormente, o NCA também era um dos coletivos que integravam a rede CVP. Além de Daniel, o NCA era formado pelos realizadores Diego Soares e Fernando Solidade. Todos moradores de regiões localizadas no extremo sul da capital paulista. Ver detalhes em
} 
Os caras, principalmente dessas oficinas [de formação audiovisual, ministradas por ONGs], vieram com essa coisa de que todo mundo já falou de favela e agora eles estavam trazendo essa ideia de que dariam o direito da gente falar, mas eles vendem, sabe? Era isso, eles vendiam a oficina. Eles tinham a aquisição dos equipamentos e a gente tinha o olhar, que depois virava uma propaganda para as próprias instituições, não é? Eu era aquele menininho que vinha com o carimbo do Itaú, da Camargo Correia e eles iam carimbando porque depois a gente virava dado para as próprias propagandas do Itaú, onde eles diziam [imita]: "Olha, o Itaú apoia o jovem da quebrada que saiu com a câmera na mão" (Daniel Fagundes, coletivo NCA, entrevista ao autor, grifos meus).

Tais considerações costumavam, com frequência, serem explicitadas por esses sujeitos em discursos públicos, assim como em textos postados em blogs e redes sociais, entre outras manifestações críticas, que demonstravam como eles possuíam uma profunda reflexividade a respeito das relações assimétricas de força, envolvidas em torno da circulação de suas produções, assim como deles próprios, na medida em que passavam a ser identificados como "realizadores audiovisuais da periferia" ou, simplesmente, como "jovens de projeto". E foi justamente o desencanto e a sensação de desamparo em relação à linguagem dos "projetos sociais" que estimulou a criação da supracitada rede CVP.

Conforme mostrei em trabalhos anteriores (ADERALDO, 2016, 2017a, 2017b, 2017c, 2017d), seus fundadores tinham a clara intenção de se valer da rede para desenvolver um espaço alternativo, capaz de funcionar como um canal autônomo de trocas e organização de ações coletivas entre pessoas interessadas no uso político de ferramentas audiovisuais. O que, efetivamente, aconteceu (não sem controvérsias) durante o período pesquisado.

Essas situações conflituosas entre jovens ativistas culturais e um conjunto diversificado de instituições evidenciaram, portanto, o fato de que as experiências biográficas dessas pessoas eram saturadas de relações de poder. O que me levou a entender que eu só poderia compreender tais relações em sua devida complexidade, na medida em que, ao invés de sucumbir à obsessão identitária de

Aderaldo (2016, 2017a, 2017b, 2017c, 2017d). O blog do grupo também pode ser consultado no seguinte endereço: http://ncanarede.blogspot.com, acessado em 5 dez. 2018. 
vincular meus interlocutores a categorias normativas a priori, tais como “jovens realizadores de periferia" ou "jovens moradores de periferia” - como muitos pesquisadores interessados apenas nas suas produções costumavam fazer àquela altura -, eu passasse a deslocar meu ponto de observação para suas experiências citadinas, buscando me mover com eles pela cidade, com a finalidade de compreender como negociavam a sua diferença, de forma diferente, a cada escala atravessada. Quando iam, por exemplo, promover alguma atividade de teor mais engajado politicamente, quando saiam para buscar trabalho (geralmente em instituições do terceiro setor), ou quando desenvolviam projetos com vistas a acessarem certos financiamentos culturais voltados às populações "periféricas".

A escolha epistêmica de me mover com os sujeitos foi, neste caso, o que permitiu que eu, gradualmente, reparasse no modo como um mesmo ator poderia se valer de diferentes acepções do conceito de "periferia". Em certos ambientes interacionais, marcados por vínculos políticos mais sólidos, como um ato público numa ocupação protagonizada por movimentos de luta por moradia, por exemplo, a "periferia" podia ser representada como sinônimo de uma "comunidade política" mais aberta, decorrente da "identificação" mútua de populações marcadas pela experiência da falta de igualdade no campo do acesso aos direitos. Já em outros ambientes, institucionais, quando interesses econômicos e profissionais estavam em jogo, a mesma categoria podia ser usada como sinônimo de uma "identidade" mais fechada e circunscrita a territórios fixos, sendo, não raro, associada a ideias como "vulnerabilidade social" e "carência".

Das reflexões que os jovens produziam, com base no acúmulo dessas experiências itinerantes, surgiam também formas de classificação muito interessantes e esclarecedoras para os propósitos da pesquisa, como a que eles faziam ao diferenciarem o que entendiam como "mercado da periferia" daquilo que caracterizavam como sendo a "periferia do mercado". A rede do vídeo popular, por exemplo, tinha como objetivo firmar-se como um espaço identificado com o princípio da "periferia do mercado", onde as experiências emancipatórias e as ações insurgentes deveriam prevalecer sobre interesses meramente utilitários ou profissionais. 
Talvez por isso, ao menos durante o período que acompanhei a rede, meus interlocutores puderam fazer do CVP um ambiente de coalizão muito criativo que - sobretudo a partir da obtenção de um financiamento público voltado ao incentivo de iniciativas culturais em áreas marginalizadas ${ }^{9}$ - se desdobrou em uma série de ações práticas, como: 1) uma revista intitulada Revista Vídeo Popular (Figura 1);2) um circuito de exibição e debate de vídeos em espaços ocupados por populações marginalizadas (albergues, favelas, sedes de movimentos sociais, ocupações, bares, bibliotecas comunitárias etc.); 3) confecção de bolsas com os DVDs dos filmes que produziam, separados por áreas temáticas; e 4) um evento anual, com convidados, batizado como Semana do Vídeo Popular.

\section{Figura 1: Capa da revista Vídeo Popular}

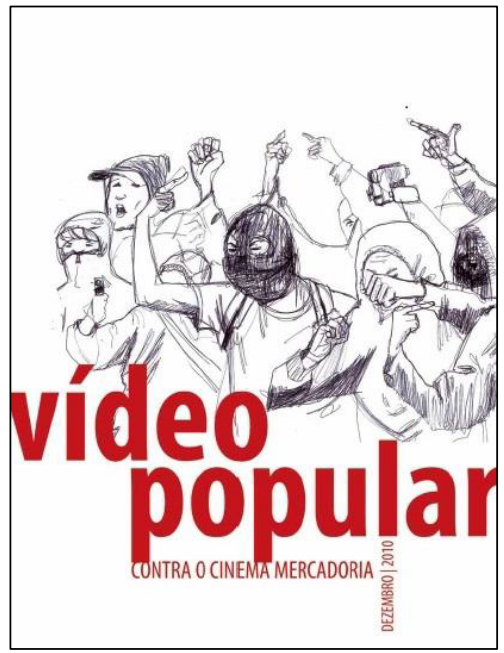

Créditos: Coletivo de Vídeo Popular.

\footnotetext{
Refiro-me ao Programa para a Valorização de Iniciativas Culturais (VAI). Trata-se de uma lei municipal, lançada no ano de 2004 pelo então vereador Nabil Bonduki, durante a gestão da prefeita Marta Suplicy, que se destaca por privilegiar agrupamentos não formalizados juridicamente, o que significa que as verbas são repassadas diretamente aos coletivos contemplados, sem a necessidade de intermediários, através de um dos membros que se inscreve na condição de "proponente". O uso desses subsídios, que posteriormente devem constar em uma prestação de contas ao município, pode ser alocado de muitas maneiras, como na aquisição de equipamentos comprovadamente essenciais para a execução do projeto. Atualmente existem duas modalidades de financiamento no programa, sendo uma (VAI I), mais voltada a jovens que tentam a obtenção dos recursos pela primeira vez e outra (VAI II), para grupos mais "profissionais", ou que já obtiveram o referido financiamento. Mais informações em: http://programavai.blogspot. com.br, acessado em 24 nov. 2018. A esse respeito ver também Raposo e Aderaldo (2019).
} 
Acompanhei essas ações durante três anos, e uma das coisas mais importantes que pude notar, como desdobramento do fortalecimento das trocas estabelecidas entre os membros da rede, foi o modo pelo qual o uso de tecnologias comunicativas permitiu a estes realizadores ao mesmo tempo ampliar suas circulações pela cidade e relacionar territórios e populações que, apesar da descontinuidade em termos geográficos/espaciais, mantinham entre si uma profunda proximidade simbólica e política como, por exemplo, uma ocupação urbana na região central e uma favela em algum dos extremos da metrópole.

Neste sentido, foi interessante notar que, mediante o desenvolvimento dessas "pontes comunicativas" promovidas pelo CVP, seus integrantes passaram a se contrapor cada vez mais aos usos irrefletidos e às definições a priori da noção de "periferia", dado o risco de apagamento das dinâmicas sociais decorrentes da experiência da desigualdade, em prol da essencialização de supostas diferenças "culturais", as quais favoreceriam o mercado das identidades, nos termos da indústria cultural hegemônica.

Consequentemente, a "periferia" que os sujeitos da pesquisa buscaram notabilizar nos encontros e discussões que acompanhei, assim como em alguns filmes, falas e textos que publicavam, dizia respeito, não à espaços geográficos fixos e marcados por uma situação de carência ou de vulnerabilidade e nem a um ambiente caracterizado pela presença de "autenticidades preservadas" (FREIRE-MEDEIROS, 2007), como costumava aparecer nas ONGs, mas, principalmente, a uma experiência social urbana marcada pelo acesso desigual aos direitos.

Deixar de pensar a "periferia" apenas como um "território geográfico" ou uma "identidade cultural" fixos e passar a entendê-la, sobretudo, como uma "experiência" caracterizada pela desigualdade no campo do acesso a direitos implicava, portanto, em considerar que ela própria (a "periferia") poderia ser vista por todos os cantos da capital paulista, através de evidências como a população de rua, as ocupações urbanas, os vendedores ambulantes etc. Desta maneira, a "periferia" passava a ser encarada não mais como um "outro" ontológico (ou seja, em essência) daquilo que seria "a cidade", mas como uma posição epistêmica e relacional, caracterizada pela contiguidade 
espacial e narrativa entre lugares e populações marcados por processos de subalternização, que envolviam a metrópole como um todo. Tratar-se-ia, assim, de um lugar epistêmico/intelectual, a partir do qual a própria urbe e sua paisagem segregada poderiam ser pensadas relacionalmente, para além das definições normativas e estanques dadas pelos especialistas (arquitetos, urbanistas, administradores etc.).

Nesses termos, portanto, a "periferia" passava a ser encarada como uma presença insurgente, responsável por nos lembrar continuamente da artificialidade subjacente à conservação dos privilégios característicos daquilo que costumamos designar como "centro".

Logo, o que pude constatar na pesquisa foi o fato de que os sujeitos envolvidos com a rede CVP, mais do que simplesmente realizar e exibir filmes nas margens de São Paulo, foram capazes de disputar com os saberes hegemônicos os sentidos relacionados às formas de compreender e conceituar esta cidade e sua paisagem desigual. Argumentei, naquela altura, que mais do que uma mera ferramenta de produção de representações, as câmeras, neste caso específico, foram transformadas por meus interlocutores em verdadeiros dispositivos epistêmicos, voltados à reflexão mais abrangente sobre o fenômeno urbano e suas fronteiras.

Um dado curioso é que a conclusão deste trabalho, publicado posteriormente como livro, se daria em pleno 2013, pouco depois das manifestações multitudinárias que ficaram conhecidas em todo o país (e também fora) como "jornadas de junho", e que se transformaram num marco referencial para o surgimento de uma nova leva de coletivos e ações voltadas ao ativismo cultural urbano em várias partes do Brasil, principalmente num momento em que os dois principais megaeventos esportivos globais (Copa do Mundo e Olimpíadas) estavam programados para acontecer no território nacional ${ }^{10}$.

\footnotetext{
10 Uma outra referência interessante a respeito destes desdobramentos políticos e associativos, gerados no pós 2013, pode ser consultada no artigo de Barreto (2018), onde a autora reflete, mais especificamente, sobre o caso das ocupações organizadas por estudantes universitários em 2016, usando como exemplo a extensa ocupação do Instituto de Ciências Humanas da Universidade Federal Fluminense (UFF), na cidade de Niterói.
} 
Foi nesse momento que passei a me interessar, particularmente, pelas práticas de ativismo contrageográfico, que configuram uma outra modalidade de atuação artístico-ativista, que, contudo, dialoga de forma muito direta com o videoativismo discutido neste primeiro tópico, no sentido de que ambos se voltam à tentativa de interpelar simbólica e intelectualmente os saberes hegemônicos sobre a cidade e as forças invisíveis responsáveis pela conservação das desigualdades constitutivas desta última.

Tais práticas "contrageográficas" consistem em ações que visam, por meio do uso "tático" (DE CERTEAU, 1994) de dispositivos tecnológicos, gráficos e visuais diversos, transformar as engrenagens de poder que conformam os territórios e populações marginalizadas em estruturas visíveis. O que pode ser feito de várias formas, desde o uso de megaprojeções com dizeres e imagens de conteúdo político em diferentes suportes urbanos ${ }^{11}$, até a elaboração colaborativa de cartografias com conteúdos insurgentes, que é a forma que escolhi para discutir no tópico que segue.

\section{ATIVISMOS CONTRAGEOGRÁFICOS E FORMAS EPISTÊMICAS DE RESISTÊNCIA}

Existem ao menos três princípios fundamentais com os quais as práticas contrageográficas operam. O primeiro deles é a ideia de que o espaço não pode ser pensado apenas como uma superfície lisa e homogênea, uma vez que, como diz a geógrafa feminista britânica Doreen Massey (2008, p. 23), se nós pensarmos o espaço somente como "a terra que se estende ao nosso redor", ou seja, como uma forma estática e autoevidente, acabamos, facilmente, levados a pensar que lugares, povos e culturas não passariam de simples fenômenos imobilizados sob essa superfície e desprovidos de história, os quais estariam vivendo perpetuamente à espera de algo externo (a chegada do conquistador

\footnotetext{
${ }^{11}$ Refiro-me aqui a suportes como uma fachada de prédio, um monumento, um muro ou um veículo, por exemplo. Para mais detalhes, ver Aderaldo (2017c).
} 
europeu, o grande capital, ou o empresário “socialmente responsável” e seu "projeto social", por exemplo).

Em outras palavras, entender que o território é uma simples superfície corresponde a acreditar que o trajeto que liga os pontos A e B num mapa, como lembra Tim Cresswell (2006, 2009), seria experienciado da mesma maneira por um empresário branco e por uma empregada doméstica negra. Não é necessário tanto esforço, portanto, para compreendermos que, em realidade, os fenômenos espaciais decorrem de relações muito mais complexas, as quais nos permitem entender que os lugares não podem ser encarados simplesmente como um "contexto" ou como um "cenário", justamente porque seu sentido é sempre razão de disputas e litígios entre agentes que ocupam posições assimétricas no jogo social.

O segundo princípio que considero importante fixar, para entendermos os fundamentos subjacentes às ações contrageográficas em tela é o de que os mapas não são os territórios e sim representações criativas, fundamentadas em perspectivas particulares e interesses específicos sobre a terra e os recursos que ela oferece.

Já o terceiro princípio a ser considerado reside no fato de que as cartografias hegemônicas nomeiam e hierarquizam populações e territórios (quase sempre) com o objetivo de controlá-los, e, ao fazê-los, produzem regimes de visibilidade, mas também zonas de invisibilidade, às quais podemos considerar como verdadeiros "pontos cegos" na experiência social.

Em linhas gerais, portanto, o que esses três princípios mostram é que todas as formas de saber que, de alguma maneira, lidam com o espaço, constroem e não somente alcançam o seu objeto. E no Brasil, metrópoles como Rio de Janeiro e São Paulo oferecem uma série de exemplos para que nós possamos entender essas questões de maneira muito concreta.

Nos últimos anos, por exemplo, o Rio de Janeiro vem sendo usado como um "laboratório" para a implantação de todo tipo de experimentações envolvendo políticas urbanas, ações militares, além do desenvolvimento de sistemas tecnológicos de controle e monitoramento, que são fatores que foram 
significativamente potencializados pelos dois megaeventos globais (Copa do Mundo e Olimpíadas) que recentemente adotaram a cidade como principal $\operatorname{sede}^{12}$.

Neste sentido, a paisagem da capital carioca tem sido constantemente marcada pela presença de uma série de mecanismos de contenção, os quais assumem formas mais ou menos visíveis. Podemos, por exemplo, pensar nos muros escondendo ou cercando favelas inteiras, mas também na interrupção de determinadas linhas de ônibus responsáveis por ligar áreas periféricas a regiões mais nobres, na zona sul. Similarmente, é possível pensar nos sistemas eletrônicos de vigilância e monitoramento, que se encontram espalhados por todos os lados. Mas o ponto é que essas formas de contenção física convivem, cotidianamente, com outras formas de contenção simbólica, as quais atingem o nosso imaginário, amiúde, sem que nos demos conta disso.

Um caso recente, em que tais desdobramentos tornam-se evidentes, é o dos mapas lançados pela empresa pública de turismo Riotur, em catálogos distribuídos a turistas, nos quais as favelas foram simplesmente apagadas da cidade, deixando de fora da paisagem cerca de 1,4 milhões de pessoas, ainda que as mesmas favelas continuassem sendo destacadas no catálogo dos chamados "tours especiais" ou "tours de realidade" oferecidos como atração pela mesma empresa ${ }^{13}$.

Outro caso interessante foi trabalhado em uma pesquisa recentemente produzida pelo geógrafo gaúcho Rogério Haesbaert, que após avaliar durante um ano todas as notícias envolvendo favelas nos dois principais jornais diários do Rio pôde constatar que havia uma seletividade evidente na cobertura geográfica de cada diário. Enquanto o jornal O Dia, voltado a um público de perfil mais popular, tendia a cobrir as favelas em sua quase totalidade, o jornal $O$ Globo, que representa a visão das elites da cidade, cobria, em $99 \%$ dos casos,

\footnotetext{
${ }_{12}$ Uma enorme quantidade de pesquisas relacionadas aos impactos urbanos desses processos foi desenvolvida nos últimos anos. Para ficar em poucos exemplos, cito Haesbaert (2014), De Tommasi e Velazco (2013) e Vainer (2011).

13 Para mais detalhes, ver: https://oglobo.globo.com/rio/folheto-da-riotur-distribuido-turistas-tira-favelas-da-geografia-da-cidade-21806418, acessado em 24 nov. 2018. Sobre a complexidade envolvida nos chamados "tours de realidade", ver especificamente Freire-Medeiros (2007).
} 
somente as favelas localizadas nas áreas urbanas mais valorizadas, ou seja, na zona sul e no centro, o que levou o pesquisador a concluir que:

O Globo, ao invisibilizar ou minimizar as ocorrências em boa parte do espaço urbano, pode trazer também sérias implicações no direcionamento das políticas públicas. Enquanto principal jornal diário formador de opinião no Rio de Janeiro - especialmente em relação às classes mais favorecidas e influentes - ele, de alguma forma, direciona o olhar do Estado para aquilo que, midiaticamente, é produzido e veiculado como sendo a informação, o problema ou o espaço mais relevante da cidade. Se a representação das questões básicas privilegia ou aparece vinculada apenas a algumas áreas, é para elas, "naturalmente", que se dirigirá, de forma prioritária, a ação do Estado (HAESBAERT, 2014, p. 265).

Situações assim, conforme adiantei, revelam como nossas percepções cotidianas são influenciadas por representações cartográficas associadas aos interesses de setores sociais dominantes sem que, muitas vezes, sequer nos demos conta disso. E é nessa brecha que os coletivos dedicados a práticas contrageográficas buscam atuar, utilizando mecanismos cartográficos e instrumentos gráficos e digitais de comunicação, com o intuito de evidenciarem os efeitos perversos dessas representações e seus consequentes desdobramentos securitários.

Em 2016, por exemplo, uma ação coletiva elaborada pelo Comitê Popular da Copa e das Olimpíadas ${ }^{14}$, denominada "O Rio de Janeiro dos Jogos da Exclusão" (Figura 2), produziu um mapa no qual o altíssimo custo político, urbanístico e social envolvido no projeto da chamada "cidade olímpica" foi transformado numa estrutura passível de ser visualizada cartograficamente.

No referido mapa - cuja plataforma on-line é dotada de uma série de recursos interativos -, é possível ver desde as desapropriações até os casos confirmados de trabalho análogo à escravidão nas obras, além dos crimes ambientais e da ocupação militar, responsável pela criação de um cinturão caracterizado,

${ }^{14}$ O Comitê Popular da Copa e Olimpíadas Rio foi uma experiência de organização coletiva, formada por um conjunto de organizações e lideranças populares, com o objetivo de discutir estratégias para enfrentar o modelo excludente de política urbana implementada no Rio de Janeiro, com base em imaginários centrados na ideia de "cidade global", para os chamados megaeventos esportivos. 
de um lado, pela repressão das áreas mais pobres, e de outro, pela "proteção" das regiões turísticas e mais valorizadas; o que evidencia como o projeto de militarização urbana nunca teve como foco a segurança da população como um todo, conforme anunciado pelos poderes oficiais ${ }^{15}$.

\section{Figura 2: Mapa Rio de Janeiro dos Jogos da Exclusão}

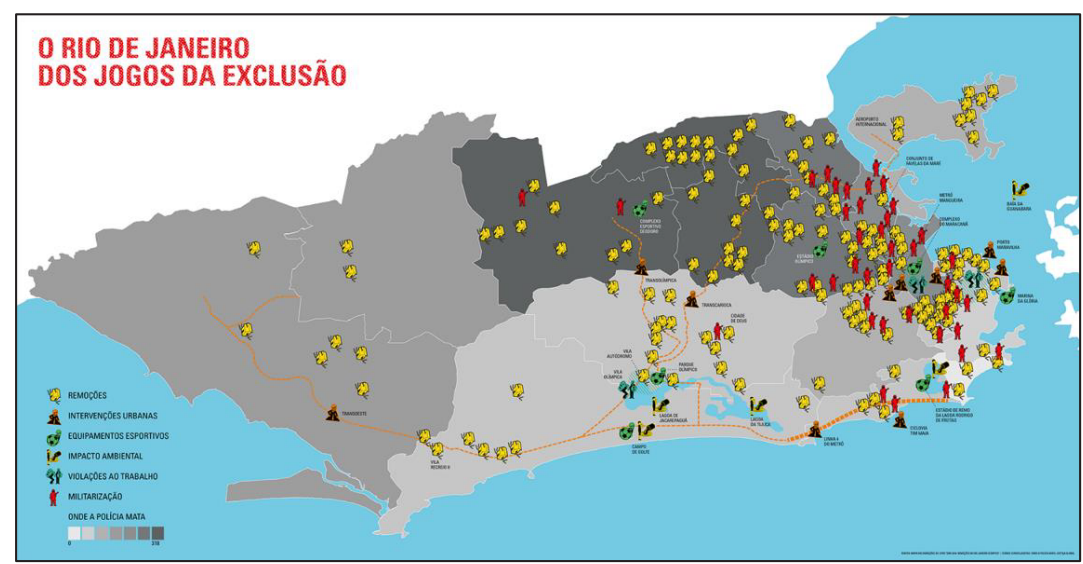

Créditos: Comitê Popular da Copa e Olimpíadas do Rio.

Outra peça cartográfica relacionada ao urbanismo militar característico do Rio foi produzida, alguns anos antes do mapa retratado acima, pelo coletivo de luta antirracista Frente 3 de Fevereiro (Figura 3). Na ocasião, o mencionado coletivo buscou relacionar os interesses por trás do modelo urbanístico característico da cidade a todo um imaginário racista e classista, fortemente reproduzido e naturalizado pela indústria cultural hegemônica.

Essa mesma cartografia também buscou aproximar as ações militares no Rio ao processo de ocupação do Haiti pelas tropas do exército brasileiro, uma vez que sua atuação nesse país foi utilizada como "laboratório" para uma

\footnotetext{
15 O supracitado mapa, assim como as informações detalhadas a seu respeito, podem ser consultados neste endereço eletrônico: https://medium.com/@jogosdaexclusao/o-rio-de-janeiro-dos-jogos-da-exclusão-104624e70 (Acessado em 24/11/2018).
} 
série de práticas e experimentos que, posteriormente, seriam implementados nas favelas cariocas ${ }^{16}$.

\section{Figura 3: Cartografia Mundo Brasil/Brasil Mundo}

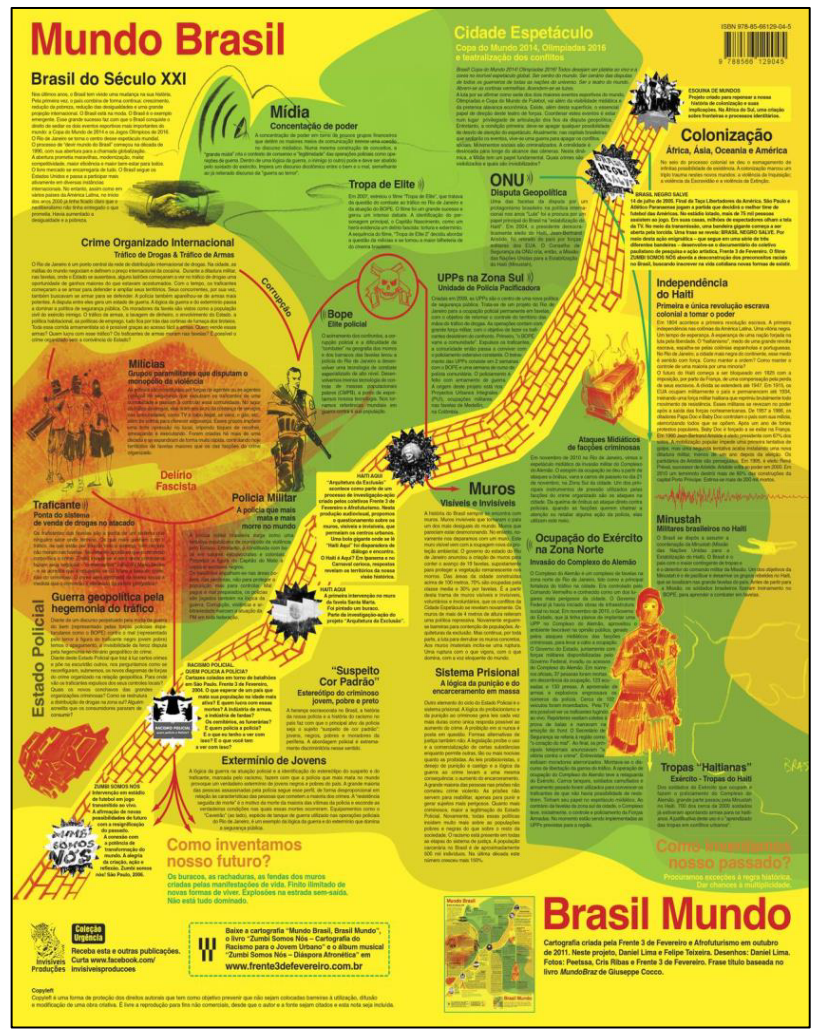

Créditos: Frente 3 de Fevereiro.

Já em São Paulo, também no contexto de preparação da cidade para a Copa do Mundo, uma ação independente e colaborativa promovida, inicialmente, por uma jornalista e ativista social chamada Patrícia Cornils e pelo programador Pedro Moraes gerou um importante impacto social. Ao perceberem que uma série de incêndios vinham acontecendo em favelas da cidade, numa

\footnotetext{
${ }^{16}$ Uma visão detalhada da cartografia pode ser consultada no seguinte endereço eletrônico: https://issuu. com/invisiveisproducoes/docs/mundo_brasil_brasil_mundo (Acesso em 24/11/2018).
} 
velocidade e com uma regularidade impressionantes, a dupla decidiu cruzar os dados desses incêndios com o das mudanças no valor do solo e criou um mapa interativo ao qual deram o nome de "Fogo no Barraco", onde era possível verificar claramente como os incêndios estavam diretamente relacionados com o circuito da especulação imobiliária na cidade. A mobilidade dos empreendimentos imobiliários foi, assim, contraposta à mobilidade forçada das populações mais pobres, embaralhando a rigidez da diferenciação centro/periferia ${ }^{17}$.

\section{Figura 4: Mapa Fogo no Barraco}

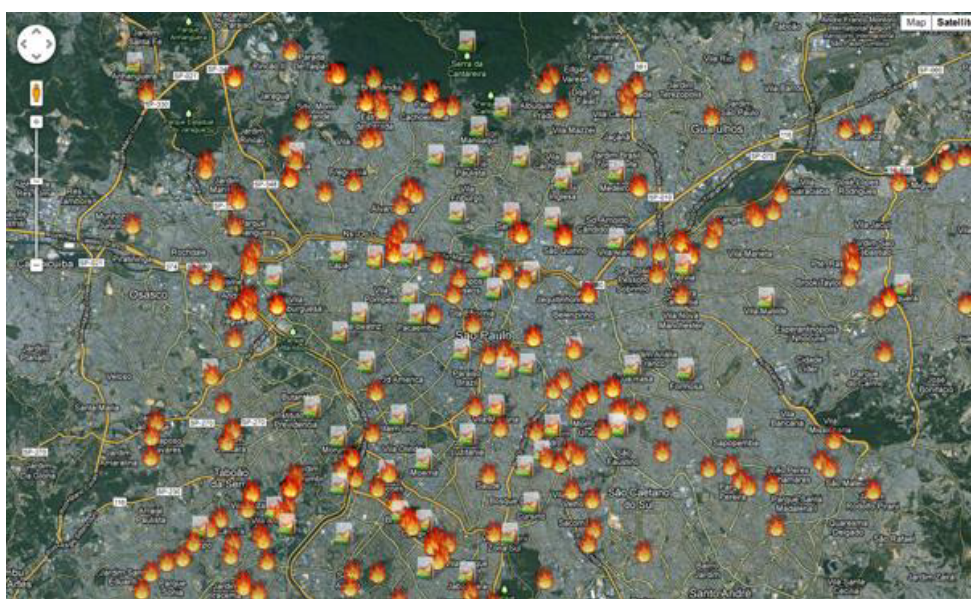

Créditos: Patrícia Cornils e Pedro Moraes.

Tais modalidades de experimentação contrageográfica tem ganhado, nos últimos tempos, uma enorme abrangência em diversos países, o que abriu margem para o surgimento de muitas coletividades de (contra)mapeadores ao redor do mundo, os quais, além de trocarem conteúdos entre si, também costumam criar encontros e planejar ações conjuntas. Desse modo, os circuitos desenvolvidos por esses sujeitos têm, igualmente, gerado seus próprios intelectuais, assim como teorias e pedagogias militantes que, embora se aproximem,

\footnotetext{
${ }^{17}$ Apesar da descontinuidade da iniciativa e do encerramento do site que havia sido criado pela dupla responsável pela produção da cartografia, ainda existem diversas matérias sobre a experiência na internet, por exemplo, a que pode ser consultada por meio do acesso ao seguinte link: http://misturaurbana. com/2012/09/fogo-no-barraco/, acessado em 24 nov. 2018.
} 
de certo modo, dos léxicos comumente partilhados por pesquisadores, "revelam potencialmente diferenças a serem evidenciadas e analisadas", como argumenta Heitor Frúgoli Jr. (2018, p. 76), ao discutir outras experiências contemporâneas de ativismo.

Entre 2017 e 2018 pude passar um ano na cidade de Buenos Aires/ Argentina, investigando uma dupla de ativistas e comunicadores chamada Iconoclasistas ${ }^{18}$, que é reconhecidamente uma das principais referências em relação a essa dimensão mais teórica e educativa relacionada à produção colaborativa de mapeamentos críticos.

Essa dupla, formada pela comunicadora e professora universitária Julia Risler, e por seu companheiro, o designer gráfico Pablo Aires, passou a atuar em 2006 e, em 2013, após participarem de uma variedade de ações públicas, decidiram trabalhar no desenvolvimento de plataformas intelectuais e ferramentas conceituais destinadas à ação política, se voltando, principalmente, a atividades de formação, produção e distribuição de manuais, cartilhas e métodos de mapeamento, nos quais, além de apresentarem reflexões sobre uma conjuntura diversa de problemáticas (urbanas, ambientais, de gênero etc.), ainda sistematizam modelos para que grupos, associações e indivíduos de todo o mundo, possam aplicar concretamente esses conhecimentos em suas respectivas áreas de atuação, adaptando-os de acordo com seus interesses ${ }^{19}$.

No período que passei na Argentina convivi de maneira bastante próxima com a mencionada dupla de artistas-ativistas e, assim, pude participar de algumas das oficinas de mapeamento que eles, eventualmente, promovem em diversos lugares, além de entrevistá-los e acompanhá-los em uma série de eventos e debates na capital do país (Figura 5). E essa experiência revelou, entre outras coisas, que o que é chamado de "mapa" nas oficinas, não tem necessariamente a ver com as estruturas bidimensionais que nós aprendemos nas aulas de geografia na escola. Um "mapa" é, nos termos utilizados por meus interlocutores,

\footnotetext{
18 Para mais detalhes, ver: https://www.iconoclasistas.net, acessado em 24 nov. 2018.

19 Uma das principais produções da dupla, neste sentido, é o "Manual de mapeo" que desenvolveram, publicaram e distribuíram, em espanhol e inglês, na internet, sob licença Creative Commons, em 2013. O mesmo pode ser consultado e baixado no seguinte endereço: http://www.iconoclasistas.net/mapeo-colectivo/, acessado em 24 nov. 2018.
} 
qualquer suporte gráfico que possibilite a visualização dos diagramas de força responsáveis por gerar efeitos de poder sobre uma determinada problemática ou realidade material. Neste sentido, o próprio corpo, assim como uma trajetória biográfica, um trajeto urbano ou uma memória podem, por exemplo, ser transformados em mapas.

Por meio de dinâmicas e exercícios inspirados nas teorias feministas, nos estudos pós-coloniais e decoloniais, assim como na pedagogia de educadores como Paulo Freire, o que se busca nessas experiências ${ }^{20}$ é, portanto, evidenciar o fato de que o invisível possui uma materialidade que, por sua vez, pode ser mostrada graficamente, por meio de dinâmicas reflexivas e da produção de diálogos que se desdobrem em relatos coletivos sobre realidades e experiências sociopolíticas compartilhadas.

\section{Figura 5: Oficina de Mapeamento, ministrada no Centro Cultural Ricardo Rojas}

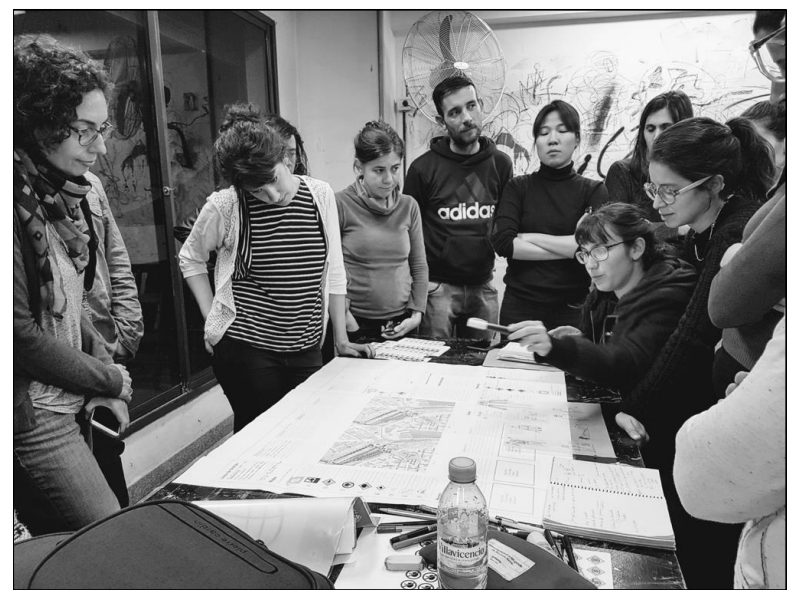

Créditos: Guilhermo Aderaldo.

Trata-se, por conseguinte, de iniciativas inspiradas naquilo que Jacques Rancière designou como "partilha do sensível". Cito abaixo uma passagem na qual o referido autor explica essa ideia:

\footnotetext{
${ }^{20}$ Uma análise detalhada do conteúdo dessas intervenções não cabe nos limites deste artigo, todavia, tenho como objetivo realizar este feito em publicações futuras.
} 
O cidadão, diz Aristóteles, é quem toma parte no fato de governar e ser governado. Mas uma outra partilha precede esse tomar parte: aquela que determina os que tomam parte. $\mathrm{O}$ animal falante, diz Aristóteles, é um animal político. Mas o escravo, se compreende a linguagem, não a "possui". Os artesãos, diz Platão, não podem participar das coisas comuns porque eles não têm tempo para se dedicar a outra coisa que não seja o seu trabalho. Eles não podem estar em outro lugar porque o trabalho não espera. A partilha do sensível faz ver quem pode tomar parte no comum em função daquilo que faz, do tempo e do espaço em que essa atividade se exerce. Assim, ter essa ou aquela "ocupação" define competências ou incompetências para o comum. Define o fato de ser ou não visível num espaço comum dotado de uma palavra comum etc. Existe, portanto, na base da política uma "estética" que não tem nada a ver com a "estetização política" própria à "era das massas", de que fala Benjamin. Essa estética não deve ser entendida no sentido de uma captura perversa da política por uma vontade de arte, pelo pensamento do povo como obra de arte. Insistindo na analogia, pode-se entendê-la num sentido kantiano - eventualmente revisitado por Foucault como o sistema das formas a priori determinando o que se dá a sentir. É um recorte dos tempos e dos espaços, do visível e do invisível, da palavra e do ruído que define ao mesmo tempo o lugar e o que está em jogo na política como forma de experiência (RANCIÈRE, 2005, p. 16).

O “estético", nesse caso, se refere, portanto, a um sistema de formas a priori, responsáveis por determinar o que nós vemos e também o que não vemos, as vozes que escutamos e também aquelas que associamos a ruídos inaudíveis. Assim, de acordo com o autor franco-argelino, o político possui uma dimensão estética que lhe é inerente, já que toda ação política consiste, ao mesmo tempo, numa intervenção e numa luta sobre o sensível. É neste sentido que todos os atores apresentados ao longo deste artigo nos convidam a, sistematicamente, pensarmos além do dado, abrindo passagem para acessarmos outras possibilidades cognitivas e, através delas, outras formas de interpretação das realidades que costumamos naturalizar em nossas vidas cotidianas. 


\section{À GUISA DE CONCLUSÃO}

Em um artigo relativamente recente, intitulado "Subjetividade e crítica cultural", a antropóloga norte americana Sherry Ortner (2007) relaciona as reflexões de Frederic Jameson (1984) e Richard Sennett (2015), com vistas a mostrar o modo como estes autores, apesar de suas consideráveis diferenças, se aproximam em relação ao diagnóstico que fazem dos efeitos do chamado "capitalismo tardio" ou "flexível” na subjetividade humana. De acordo com Ortner, tanto Jameson, quanto Sennett chegam à conclusão de que a experiência do capitalismo tardio é, em essência, desorientadora.

Para Sennett (2015), por exemplo, a nova "cultura corporativa", baseada na noção de "flexibilidade" e no princípio que o autor resume por meio da frase "sem longo prazo", se ramifica de diversas formas na consciência coletiva. Nesse sentido, a mentalidade "flexível", segundo este autor, requer sujeitos que aceitem a fragmentação e o desapego da memória histórica, uma vez que se caracteriza pela reengenharia constante das atividades produtivas e pelo fim das relações duradouras e rotineiras. Nessa lógica, os sujeitos nunca sabem ao certo o que se espera deles e se sentem sempre em dívida com o presente, uma vez que devem se "atualizar" constantemente e competir ininterruptamente. Perdem, assim, a capacidade de perceber o trabalho, além de aspectos essenciais da vida cotidiana, na sua totalidade.

A crise de consciência pós-moderna, portanto, corresponderia, de acordo com estes autores, a "uma crise de orientação num mundo não interpretável ou ilegível” (ORTNER, 2007, p. 397). E como forma de combater o efeito corrosivo desta "crise" subjetiva, tanto Jameson quanto Sennett sugerem a elaboração de ferramentas conceituais, cognitivas e simbólicas voltadas ao trabalho de reorientação e reconstrução do "eu” dentro deste novo regime. Jameson chama este esforço intelectual de "mapeamento cognitivo", enquanto Sennett prefere falar em termos de um exercício de "autonarração". Todavia, em diálogo com Raymond Williams (1977), Ortner lembra-nos que há movimentos atentos a estas necessidades, os quais se enquadram na ideia que o autor inglês 
chamou de "contracorrentes", ou seja, formações culturais alternativas que têm por objetivo concorrer com a cultura dominante.

Acredito que este último ponto é o que nos permite retomar o sentido das elaborações e intervenções que venho discutindo até aqui, levando em consideração seus efeitos contrageográficos; afinal, trata-se de práticas que visam reorientar-nos, ao interpelar as próprias fronteiras e seus mecanismos (físicos e simbólicos) de regulação e controle de fluxos (de imagens, imaginários, pessoas e objetos), buscando notabilizar o modo pelo qual regimes de visibilidade (e invisibilidade), assim como formas de mobilidade (e imobilidade) são, na verdade, produzidos e naturalizados constantemente por referências culturais de teor normativo.

Logo, o exercício envolvido no ato de desnaturalizar as representações geográficas dominantes, por meio de produções audiovisuais, intervenções no espaço urbano ou da elaboração coletiva de cartografias cognitivas, implica uma tentativa de tornar legíveis outras formas de conceber, narrar e ocupar os territórios, para além da limitação característica das representações binárias.

Trata-se de práticas de "educação libertadora", no sentido dado por Bell Hooks (2013), quando esta autora fala sobre o potencial que certas experiências pedagógicas alternativas possuem de produzir efeitos de interrupção nos códigos naturalizados pelos sistemas de poder. Segundo a antropóloga mexicana Rossana Reguillo (2017a, 2017b), aliás, a “interrupção” consistiria num tipo de ação responsável por alterar as "ancoragens de sentido" do mundo, propiciando "o distanciamento frente ao que é assumido como normal ou inalterável” (REGUILLO, 2017b, p. 111).

Assim, interrupções, teriam o papel de convidar-nos a "pensar e sentir mais além do dado como certo, natural” (REGUILLO, 2017b, p. 111), abrindo passagem para outras possibilidades de interpretação do sentido dos processos responsáveis por ligar espaços e populações aparentemente descontínuos entre si.

Se, por um lado, a lógica "flexível" da cultura capitalista contemporânea busca desterritorializar o sentido dos nossos vínculos, desorientando-nos, na medida em que nos leva a perder de vista as relações, passando a enxergar, no lugar delas, apenas as formas essencializadas dos termos que relacionam 
- tais como centro/periferia, exclusão/inclusão, legal/ilegal etc. -, por outro, as ações contrageográficas caminham no sentido inverso e visam reterritorializar nossas existências, com base em uma reconstrução conceitual/cognitiva do mundo e das formas de entendimento das desigualdades que o caracterizam.

É o que acontece quando, por exemplo, uma rede como o Coletivo de Vídeo Popular se vale do uso de ferramentas audiovisuais para criar "pontes comunicativas" capazes de relacionar espaços e populações socialmente marginalizadas, por meio do reconhecimento da experiência de contiguidade política, decorrente do acesso desigual aos direitos. $\mathrm{O}$ mesmo ocorre quando uma rede como o Comitê Popular da Copa e das Olimpíadas do Rio de Janeiro torna visível, através de uma peça cartográfica, o projeto urbanístico da chamada "cidade olímpica", demonstrando a que interesses esta elaboração corresponde, ou ainda, quando uma cartografia coletiva é capaz de demonstrar a sórdida relação que aproxima o circuito da especulação imobiliária em São Paulo ao incêndio sistemático de uma série de favelas.

Todas essas práticas nos revelam que "centro" e "periferia" são faces de uma mesma moeda. E seus protagonistas são sujeitos que, apesar da evidente condição de precariedade laboral e econômica (na maioria dos casos), possuem amplos repertórios culturais, além de sofisticados conhecimentos técnicos e experiências cosmopolitas, que se dão em maior ou menor grau, dependendo do interlocutor ao qual nos referimos. A complexidade de suas experiências urbanas é, portanto, o que faz com que os mesmos se sintam, amiúde, incomodados pela normatividade implicada na reificação de certas atribuições identitárias comumente projetadas sobre eles. E isso, ao contrário de gerar paralisia, tem estimulado o desenvolvimento de reflexões, teorias e experimentações pedagógicas originais, voltadas ao desenvolvimento de novas modalidades de identificação, engajamento e formas de mobilidade, não capturáveis através de estruturas cognitivas pautadas por referências geográficas bidimensionais. 


\section{REFERÊNCIAS}

1. ADERALDO, Guilhermo. Entre imagens e imaginários: estética e política nas intervenções visuais/audiovisuais de coletivos culturais paulistanos. In: FRÚGOLI JR., Heitor; KOWARICK, Lúcio (org.). Pluralidade urbana em São Paulo: vulnerabilidade, marginalidade, ativismos. São Paulo: Editora 34: Fapesp, 2016.

2. ADERALDO, Guilhermo. Reinventando a cidade: uma etnografia das lutas simbólicas entre coletivos culturais vídeo-ativistas nas "periferias" de São Paulo. São Paulo: Annablume: Fapesp, 2017a.

3. ADERALDO, Guilhermo. Cidades em conflito: câmeras, sprays, lugares e movimentos. In: BERTELLI, Giordano Barbin; FELTRAN, Gabriel (org.). Vozes à margem: periferias, estética e política. São Carlos: EdUFSCar, 2017b.

4. ADERALDO, Guilhermo. Territórios, mobilidades e estéticas insurgentes: refletindo sobre práticas e representações coletivas de realizadores visuais nas metrópoles contemporâneas. Cadernos de Arte e Antropologia, Salvador v. 6, n. 2, p. 31-48, 2017c.

5. ADERALDO, Guilhermo. Linguagem audiovisual e insurgências populares: reconstituindo uma experiência associativa entre jovens vídeo-ativistas nas “periferias” paulistanas. Iluminuras, Porto Alegre, v. 18, n. 44, p. 74-101, 2017d.

6. AGIER, Michel. L'invention de La ville. Paris: Archieves Contemporaines, 1999.

7. AGIER, Michel. Antropologia da cidade: lugares, situações, movimentos. São Paulo: Terceiro Nome, 2011.

8. AGIER, Michel. La condition cosmopolite: l'anthropologie à l'épreuve du piège identitaire. Paris: Éditions La Decouverte, 2013.

9. AGIER, Michel. Do direito à cidade ao fazer cidade: o antropólogo, a margem e o centro. Mana, Rio de Janeiro, v. 21, n. 3, p. 483-498, 2015.

10. ARANTES, Antonio. A guerra dos lugares. In: ARANTES, Antonio. Paisagens paulistanas: transformações do espaço público. Campinas: Papirus, 2000.

11. AUGÉ, Marc. Por uma antropologia da mobilidade. Maceió: Edufal: Editora Unesp, 2010.

12. BARRETO, Alessandra. Ocupa ICHF: processos de luta e artes de fazer entre estudantes universitários em Niterói, Rio de Janeiro. In: GONÇALVES, Renata; FERRO, Ligia (org.). Cidades em mudança: processos participativos em Portugal e no Brasil. Rio de Janeiro: Mauad, 2018. p. 177-196.

13. BUTLER, Judith. Cuerpos aliados y lucha política: hacia una teoría performativa de la asamblea. Ciudad Autonoma de Buenos Aires: Paidós, 2017. 
14. CARMO, Renato Miguel. Do espaço abstrato ao espaço compósito: reflectindo sobre as tensões entre mobilidades e espacialidades. In: CARMOS, Renato Miguel; SIMÕES, José Alberto (org.). A produção das mobilidades: redes, espacialidades e trajectos. Lisboa: ICS, 2009. p. 41-56.

15. CRESSWELL, Tim. On the move: mobility in the modern western world. Nova York: Routledge, 2006.

16. CRESSWELL, Tim. Seis temas na produção das mobilidades. In: CARMOS, Renato Miguel; SIMÕES, José Alberto (org.). A produção das mobilidades: redes, espacialidades e trajectos. Lisboa: ICS, 2009. p. 25-40.

17. DE CERTEAU, Michel. A invenção do cotidiano: vol. 1: artes de fazer. Rio de Janeiro: Vozes, 1994.

18. DE TOMMASI, Lívia; VELAZCO, Dafne. A produção de um novo regime discursivo sobre as favelas cariocas e as muitas faces do empreendedorismo de base comunitária. Revista Instituto de Estudos Brasileiros, São Paulo, v. 56, p. 15-42, 2013.

19. FASSIN, Didier. Compaixão e repressão: a economia moral das políticas de imigração na França. Ponto Urbe, v. 15, 2014.

20. FREIRE-MEDEIROS, Bianca. A favela que se vê e que se vende: reflexões e polêmicas em torno de um destino turístico. Revista Brasileira de Ciências Sociais, São Paulo, v. 22, p. 61-72, 2007.

21. FREIRE-MEDEIROS, Bianca; VILAROUCA, Márcio; MENEZES, Palloma. A pobreza turística no mercado da pacificação: reflexões a partir da experiência da Favela Santa Marta. Caderno CRH, Salvador, v. 29, n. 78, p. 571-585, 2016.

22. FRÚGOLI JR., Heitor. Ativismos urbanos em São Paulo. Caderno CRH, Salvador, v. 31, n. 82, p. 75-86, 2018.

23. GRAHAM, Stephen. Cidades sitiadas: o novo urbanismo militar. São Paulo: Boitempo, 2016.

24. HAESBAERT, Rogério. O mito da desterritorialização: do fim dos territórios à multiterritorialidade. Rio de Janeiro: Bertrand Brasil, 2010.

25. HAESBAERT, Rogério. Viver no limite: território e multi/transterritorialidade em tempos de in-segurança e contenção. Rio de Janeiro: Bertrand Brasil, 2014.

26. HOOKS, Bell. Ensinando a transgredir: a educação como prática da liberdade. São Paulo: Martins Fontes, 2013.

27. JAMESON, Fredric. Postmodernism, or the cultural logic of late capitalism. New Left Review, v. 146, p. 53-92, 1984. 
28. MASSEY, Doreen. Pelo espaço: uma nova política da espacialidade. Rio de Janeiro: Bertrand Brasil, 2008.

29. MASSEY, Doreen. Un sentido global del lugar. In: ALBET, Abel; BENACH, Núria (org.). Doreen Massey: un sentido global del lugar. Barcelona: Icaria Editorial, 2012. p. 112-129.

30. ORTNER, Sherry B. Subjetividade e crítica cultural. Horizontes Antropológicos, Porto Alegre, v. 13, n. 28, p. 375-405, 2007.

31. RANCIÈRE, Jacques. A partilha do sensível: estética e política. São Paulo: Editora 34, 2005.

32. RAPOSO, Otávio; ADERALDO, Guilhermo. Políticas públicas e produção artístico-cultural entre jovens das periferias de Lisboa e São Paulo. Etnográfica, Lisboa, v. 23, n. 1, p. 109-132, 2019.

33. REGUILLO, Rossana. Paisajes insurrectos. Barcelona: Moelmo, 2017a. E-book.

34. REGUILLO, Rossana. Imaginação e protesto, comunicação e subjetividade. In: ZANETTI, Daniela; REIS, Ruth (org.). Comunicação e territorialidades: poder e cultura, redes e mídias. Vitória: Edufes, 2017b. p. 107-128.

35. RISLER, Julia; ARES, Pablo. Manual de mapeo colectivo: recursos cartográficos críticos para procesos territoriales de creación colaborativa. Buenos Aires: Tinta Limón, 2013.

36. ROCHA, L. M. O repertório dos projetos sociais? Política, mercado e controle social nas favelas. In: BIRMAN, Patrícia; LEITE, Márcia; MACHADO, Carly; SÁ CARNEIRO, Sandra. (org.). Dispositivos urbanos e trama dos viventes: ordens e resistências. Rio de Janeiro: Editora FGV: Faperj, 2014. p. 291-312.

37. SENNETT, Richard. A corrosão do caráter: consequências pessoais do trabalho no novo capitalismo. Rio de Janeiro: Record, 2015.

38. SHELLER, M.; URRY, J. The new mobilities paradigm. Environment and Planning A, v. 38, n. 2, p. 207-26, 2006.

39. SIMÕES, José Alberto. Redes, internet e hip-hop: redefinindo o espaço dos fluxos. In: CARMOS, Renato Miguel; SIMÕES, José Alberto (org.). A produção das mobilidades: redes, espacialidades e trajectos. Lisboa: ICS, 2009. p. 71-90.

40. VAINER, Carlos. Cidade de exceção: reflexões a partir do Rio de Janeiro. In: ENCONTRO NACIONAL DA ASSOCIAÇÃO NACIONAL DE PLANEJAMENTO URBANO, 14., 2011, Rio de Janeiro. Anais [...]. Rio de Janeiro: Anpur, 2011. v. 14.

41. WILLIAMS, Raymond. Marxism and literature. Oxford: Oxford University Press, 1977. 